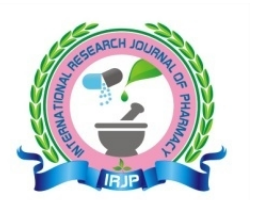

INTERNATIONAL RESEARCH JOURNAL OF PHARMACY

www.irjponline.com

ISSN $2230-8407$

\title{
Research Article \\ IMPACT OF OVER COAT APPLICATION ON ENTERIC COATED DRUG PELLETS: DESIGNED TO PROTECT FROM STOMACH ENVIRONMENT
}

Swamykannu Dinesh Mohan *1, Vangadari Rama Mohan Gupta ${ }^{2}$, Yalamanchili Manaswini ${ }^{3}$

${ }^{1}$ Department of Pharmaceutics, Vishnu Institute of Pharmaceutical Education and Research, Narsapur, Medak, Hyderabad, Telangana, India

${ }^{2}$ Department of Pharmaceutics, Pullareddy Institute of Pharmacy, Annaram, Dundigal, Medak, Hyderabad, Telangana, India

${ }^{3}$ Analytical Research division, Bioleo analytical laboratory, Prasanth nagar, Hyderabad, India

*Corresponding Author Email: dineshmohan.s@viper.ac.in

Article Received on: 21/06/16 Revised on: 21/08/16 Approved for publication: 14/10/16

DOI: $10.7897 / 2230-8407.0710115$

\begin{abstract}
Omeprazole is an antisecretory compounds called proton pump inhibitors. Omeprazole is an acid labile drug so enteric coated pellets were formulated using pan coating process. Two different groups of pellets were prepared, one group of pellets consists drug layer coat, enteric layer coat and another group of pellets consists of drug layer coat, enteric layer coat and over coat. The pellets were optimized with the acid resistance and drug release in simulated intestinal fluid as the process parameters. Other properties, such as moisture content, particle size, resistance to abrasion and drug content also studied. The over coat application played a vital role in acid resistance it protects the drug release in stomach environment. Three month accelerated stability studies, showed over coated pellets to be stable.
\end{abstract}

Key words: Omeprazole, pellets, proton pump inhibitors, enteric layer, acid resistance, drug release.

\section{INTRODUCTION}

Omeprazole (OMZ) belongs to a class of antisecretory compounds called proton pump inhibitors ("PPIs") $)^{1}$ that are prescribed for duodenal ulcers, gastric ulcers, gastroesophageal reflux disease (GERD), severe erosive esophagitis and pathological hypersecretory conditions such as Zollinger Ellison syndrome $^{2}$. The stability of $\mathrm{OMZ}$ is affected by stomach acid therefore it requires enteric coating applications ${ }^{3}$. Currently, there are many PPIs are available as gastro protected preparations which are necessary to protect the acid-labile PPI from acid degradation within the stomach namely; tablets, granules encapsulated in a gelatin shell and multiple unit pellet system moreover the available PPI formulations are considered as delayed release (DR) or Extended release preparations (ER) ${ }^{4}$. The formulations of PPIs will become an important strategy used by pharmaceutical companies, as they will be useful for the treatment of nocturnal acid secretion because of their modified release ${ }^{5}$. Multiparticulate drug delivery systems are predominantly suitable for achieving extended release oral formulations with low risk of dose deposition, flexibility of blending to get different release patterns, as well as reproducible and short gastric residence time ${ }^{6}$. Multiparticulate systems offer opportunities to improve bioavailability through the encapsulation of the API in a suitable matrix to promote solubility of the compound and can target release at the most appropriate location within the GIT for drugs with $\mathrm{pH}$ dependent solubility or a limited absorption window ${ }^{\top}$. The main objective and purpose of the present research work is to formulate OMZ delayed release pellets containing an enteric layer of methacrylic acid copolymers of Eudragit L 100 and over coat layer of HPMC.

\section{MATERIALS \& METHODS}

\section{Materials}

Omeprazole, Eudragit L 100 was kindly supplied as a gift sample by Yeluri formulations Hyderabad, India. HPMC, PEG6000 were gifted from Bioleo analytical laboratory Hyderabad, India. Other materials used were of analytical grade.

\section{Methods}

\section{Preparation of delayed release $\mathrm{OMZ}$ pellets}

Drug layering

$500 \mathrm{ml}$ of purified water was taken in a beaker and kept for stirring under a mechanical stirrer. The binding polymer of HPMC, sucrose and Di sodium hydrogen phosphate are mixed until the materials are dissolved. Then the sodium lauryl sulfate (SLS) is added to the mixture with gentle stirring to avoid the formation of foam until it dissolves completely. Finally, OMZ is added to the mixture and gently stirring is continued until the $\mathrm{OMZ}$ is completely dispersed.

\section{Enteric coating}

The required quantity of Eudragit L100 was dissolved in 415.5 $\mathrm{ml}$ of 1:1 ratio of isopropanol and acetone on a magnetic stirrer until the entire polymer is dissolved. Then the plasticizer PEG 6000 is dissolved with agitation in this solution finally talc was added.

\section{Over coating}

Eudragit L100 is brittle in dry state. Thus, if they used as enteric polymer the film can suffer from severe damages which leads to loss of enteric properties of the dosage form. To overcome this restriction previous workers in the field of enteric coating have found it necessary to over coat with a cellulose derivatives to 
prevent brittleness of the polymer and improve the stability of the product ${ }^{8}$. 2.25gms of HPMC and 3.87gms of PEG 6000 were dissolved in $207 \mathrm{ml}$ of each of isopropanol and acetone under magnetic stirrer it would be considered as an over coating solution.

\section{Coating process}

1000 gm of non-pareil seeds (NPS) were placed in the lab model conventional coating pan (PCP-12" Prism Pharma machinery, Ahmadabad, India) and the suspension containing the $\mathrm{OMZ}$ is coated at a product temperature of $35-45^{\circ} \mathrm{C}$; an atomization pressure of 1.5 bar and a pump rate of $1-25 \mathrm{ml} / \mathrm{minute}$, starting with a slow rate of pumping to avoid agglomeration and increasing the rate of pumping consistent with the avoidance of the formation of agglomerates. After coating is complete the pellets are dried at a temperature of $50^{\circ} \mathrm{C}$ for $1 \mathrm{hr}$ and coated pellets were weighed to identify the weight gain. Next, $1012 \mathrm{gm}$ of drug layered active pellets were placed coating pan and the enteric coating mixture was applied on to the drug layered active pellets, finally dried at a same temperature of $50^{\circ} \mathrm{C}$ and weighed again to know the weight gain. 1020 gm of coated pellets were divided in to two groups namely; A and A+ (50:50) $514 \mathrm{gm}$ of A+ group of pellets were coated again with over coating polymer of HPMC under the same conditions. After completion of over coating process A+ pellets were weighed and identified the weight gain. The coating composition and process utilizes for coating were shown in Table 1-4.

\section{CHARACTERIZATION AND EVALUATION OF PELLETS}

\section{Particle size and shape}

The average particle size of the pellet formulations of $\mathrm{OZ}$ were analyzed by simple sieve analysis method ${ }^{9}$. The particle size of various batches of pellets was given in the table (5). The surface roughness of pellets were studied by scanning electron microscope (SEM) (JEOL JSM - 6490 LA, Japan) to characterize the surface of the pellets and the results are shown in Figure 1,2.

\section{Loss on Drying}

The moisture content (\% loss on drying; \% LOD) of the pellets of $\mathrm{A} \& \mathrm{~A}^{*}$ was determined by using Mettler Toledo Halogen Moisture Analyzer (Model: HB43, USA) where the working temperature was $105^{\circ} \mathrm{C}$ and the results are shown in Table 5 .

\section{Resistance to abrasion}

Resistance to abrasion of the drug-layered cores or coated pellets was determined with a Roche friabilator. Briefly, $25 \mathrm{~g}$ of sample was mixed with $25 \mathrm{~g}$ of glass spheres (1.5-2 $\mathrm{mm}$ in diameter) and uniformly tumbled for $4 \mathrm{~min}$ at $25 \mathrm{rpm}$ and subsequently strained through a 40 -mesh sieve. Friability (\%) was calculated based on the percentage of weight loss. The measurements were made in triplicate.

Initial weight - Final weight / Initial weight X 100

\section{Assay}

\section{Standard preparation}

Weigh accurately about $20 \mathrm{mg}$ of OMZ working standard into $50 \mathrm{ml}$ volumetric flask and $25 \mathrm{ml}$ of $0.1 \mathrm{~N} \mathrm{NaoH}$ was added. The flask was shaken for $15 \mathrm{~min}$ and made the volume with remaining quantity of $0.1 \mathrm{~N} \mathrm{NaoH}$. $3 \mathrm{ml}$ of this solution was withdrawn and transferred in to $100 \mathrm{ml}$ of fresh volumetric flask and diluted with same solution of $0.1 \mathrm{~N} \mathrm{NaoH}$ it would be consider as a standard solution.

\section{Sample preparation}

Enteric coated and over coated pellets were weighed accurately equivalent to $20 \mathrm{mg}$ of $\mathrm{OMZ}$ in two $100 \mathrm{ml}$ volumetric flasks separately then $0.1 \mathrm{~N} \mathrm{NaoH}$ solution was added and the contents were diluted to $100 \mathrm{ml}$ and filtered through Whatman filter paper (No.41). $1 \mathrm{ml}$ of each solution was then diluted to $50 \mathrm{ml}$ of $0.1 \mathrm{~N} \mathrm{NaoH}$ solution separately. Absorbance of the sample solutions was recorded, at $302 \mathrm{~nm}$ by UV Spectrophotometer (Lambda 25, Perkin Elmer, Wellesley, (USA). Drug content was determined by following validated formula (Bioleo analytical laboratory, Hyderabad) Results of the triplicate analysis are given in Table 5.

$\begin{array}{lcccc}\text { Sample Abs } & \text { W } & 3 & 50 & 50 \\ \text { Std Abs } & 50 & 50 & \text { W }_{\text {SPL }} & 3\end{array}$

$\mathrm{W}_{\mathrm{STD}}=$ Weight of the standard taken in $(\mathrm{mg})$

$\mathrm{W}_{\mathrm{SPL}}=$ Weight of the sample taken $(\mathrm{mg})$

\section{Gastric resistance and in-vitro dissolution test}

Dissolution testing of the pellets was performed using USP Type II Dissolution apparatus (Lab India) at $75 \mathrm{rpm}$ starting with 750 $\mathrm{ml}$ solution at $37 \pm 0.5^{\circ} \mathrm{C}$. The method of preparation of the dissolution medium was as follows. First, pellets were placed in a $0.1 \mathrm{M} \mathrm{HCl}$ solution for $2 \mathrm{hrs}$ and the samples were collected every $30 \mathrm{~min}$ up to $2 \mathrm{hrs}$. Then, $250 \mathrm{ml}$ of $0.05 \mathrm{M}$ phosphate buffer was added and the $\mathrm{pH}$ was adjusted with a solution of sodium hydroxide $(\mathrm{NaOH})$ to $\mathrm{pH}$ 6.8. Samples were collected $10,15,30$ and $45 \mathrm{~min}$ finally the samples were analyzed at 302 nm by UV Spectrophotometer.

\section{Stability studies}

To investigate the influence of temperature and humidity onto the pellets. Pellets with enteric coating alone and pellets with over coating were placed in humidity chamber (Newtronics NW DSU 52) and exposed to a temperature of $40 \pm 2^{\circ} \mathrm{C}$ and also a relative humidity of $75 \pm 5 \% \mathrm{RH}$. The samples were removed from the humidity chamber at the end of $0,15,30,45$ and 60 days and checked for the shape, drug content, gastric resistant and in vitro dissolution studies and the results are shown in the Figures 5,6 .

\section{Scanning Electron Microscopy}

The micrographs of the coated pellets were taken with a scanning electron microscopy (SEM) (S-3500N, SEM, Hitachi, Tokyo, Japan) to examine the surfaces and the morphology of the pellets. The pellets were mechanically cleaved transversely and sputtered with gold for $5 \mathrm{~min}$ by a sputter.

\section{RESULTS AND DISCUSSION}

Omeprazole was loaded on NPS by solution layer technology. The prepared pellets were used to perform several physical parameters with in vitro dissolution study using the USP paddle method. Then 3 months stability study was performed at RT, $40^{\circ} \pm 2^{\circ} \mathrm{C}, 75 \pm 5 \% \mathrm{RH}$ conditions. The results were mentioned on Table 6.

\section{Physical characterization}

Initially the colour of the pellet was white to off white and there were no difference in colour was found from A and $A^{*}$. Hence, formulation variables have no effect on the colour of the pellets. Particle size of the pellets was in the range of $1685-1706 \mu$ determined by sieve analysis. The SEM result was revealed that, the enteric coated pellets were spherical in shape with rough surface (Figure 2). Whereas the over coated pellets were spherical in shape with smooth surface (Figure 1). 
Swamykannu Dinesh Mohan et al. Int. Res. J. Pharm. 2016, 7 (10)

Table 1: Formula for preparation of OMZ pellets

\begin{tabular}{|c|c|c|c|c|}
\hline S.No & Name of the materials (gm) & Drug layering & Enteric coating & Over coating \\
\hline 1 & OMZ & 213.85 & - & - \\
\hline 2 & HPMC & 2.25 & - & 2.25 \\
\hline 3 & Sucrose & 213.85 & - & - \\
\hline 4 & Mannitol & 25.65 & - & - \\
\hline 5 & SLS & 5.3 & - & - \\
\hline 6 & Eudragit L100 & - & 129.05 & 3.87 \\
\hline 7 & PEG 6000 & - & 7.74 & 207.8 \\
\hline 8 & Talc & - & 415.5 & 207.8 \\
\hline 9 & Isopropanol & - & 415.5 & - \\
\hline 10 & Acetone & 500 & - & \\
\hline 11 & P.Water (ml) & & & - \\
\hline
\end{tabular}

Table 2: Parameters of coating process

\begin{tabular}{|c|c|c|c|c|}
\hline \multirow{2}{*}{ S.No } & Parameters & \multicolumn{2}{|c|}{ Value } \\
\cline { 3 - 5 } & & Drug layering & Enteric coating & 0.5 \\
\hline 1 & Nozzle diameter $(\mathrm{mm})$ & 0.5 & 12 & 0.5 \\
\hline 2 & Pan Speed 12 RPM & 12 & 1.5 & 12 \\
\hline 3 & Atomization Pressure (bar) & 35 & 35 & 1.5 \\
\hline 4 & Inlet air temperature $\left({ }^{\circ} \mathrm{C}\right)$ & $25-30$ & $25-30$ & $25-30$ \\
\hline 5 & Outlet air temperature $\left({ }^{\circ} \mathrm{C}\right)$ & $1-25$ & $1-25$ & $1-25$ \\
\hline 6 & Spray rate $(\mathrm{ml} / \mathrm{min})$ & 45 & 100 & 45 \\
\hline 7 & Coating time in (Min) & & \\
\hline
\end{tabular}

Table 3: Composition of over coating solution

\begin{tabular}{|c|c|c|}
\hline S.No & \multicolumn{2}{|c|}{ Name of the materials and quantity in (gm) } \\
\hline 1 & HPMC & 2.25 \\
\hline 2 & Isopropanol & 207.8 \\
\hline 3 & Acetone & 207.8 \\
\hline
\end{tabular}

Table 4: \% weight gained for enteric coated and over coated pellets

\begin{tabular}{|c|c|c|c|c|}
\hline S.No & Code & Wt. gained in mg (wt/wt) & \multirow{2}{*}{ Wt. gained in \%o } \\
\hline & & Before & After & \\
\hline 1 & Drug layering & 1000 & 1012 & 1.2 \\
\hline 2 & Enteric coating & 1012 & 1028 & 1.6 \\
\hline 3 & Over coating & 514 & 519 & 0.96 \\
\hline
\end{tabular}

Table 5: Physical properties of formulation codes of $\mathbf{A} \& \mathrm{~A}^{\text {* }}$

\begin{tabular}{|c|c|c|c|}
\hline S.No & Parameters & Formulation code (A) & Formulation code (A $\left.^{*}\right)$ \\
\hline 1 & Colour & Off-white & Off-white \\
\hline 2 & Surface & Rough & Smooth \\
\hline 3 & Particle size & $1576 \pm 11$ & $1604 \pm 19$ \\
\hline 4 & LOD (\%) & $1.93 \pm 0.01$ & $1.94 \pm 0.01$ \\
\hline 5 & Resistance to abrasion (\%) & $0.792 \pm 0.00$ & $0.751 \pm 0.00$ \\
\hline 6 & Assay (\%) & $98.45 \pm 0.13$ & $99.70 \pm 0.012$ \\
\hline
\end{tabular}

Table 6: Gastric resistance and in-vitro dissolution profile of $A \& A^{*}$

\begin{tabular}{|c|c|c|c|c|c|}
\hline \multirow[t]{4}{*}{ F. code } & \multicolumn{5}{|c|}{ Amount of drug released in different dissolution media } \\
\hline & \multicolumn{3}{|c|}{ PH 1.2 } & PH 6.8 & \\
\hline & \multicolumn{3}{|c|}{ Time in Min } & $\begin{array}{r}\text { PH 6.8 } \\
\text { Time in Min }\end{array}$ & \\
\hline & 30 & 60 & 120 & 150 & 180 \\
\hline A & $7.21 \pm 0.02 \%$ & $9.87 \pm 0.03 \%$ & $16.12 \pm 0.09 \%$ & $51.01 \pm 1.15 \%$ & $86.15 \pm 1.13 \%$ \\
\hline $\mathrm{A}^{*}$ & $0 \%$ & $0 \%$ & $4.43 \pm 0.10 \%$ & $47.14 \pm 0.18 \%$ & $97.10 \pm 0.12 \%$ \\
\hline
\end{tabular}

Table 7: Accelerated stability study of A \& A* batches

\begin{tabular}{|c|c|c|c|c|c|c|c|c|}
\hline \multirow{3}{*}{ Parameters } & \multicolumn{8}{|c|}{ Storage condition: $40 \pm 2^{\circ} \mathrm{C} / 75 \pm 5 \% \mathrm{RH}$} \\
\hline & \multicolumn{2}{|c|}{ Initial } & \multicolumn{2}{|c|}{$1^{\text {st }}$ Month } & \multicolumn{2}{|c|}{$2^{\text {nd }}$ Month } & \multicolumn{2}{|c|}{$3^{\text {rd }}$ Month } \\
\hline & $\mathrm{A}$ & $\mathrm{A}^{*}$ & $\mathrm{~A}$ & $\mathrm{~A}^{*}$ & $\mathrm{~A}$ & $\mathrm{~A}^{*}$ & $\mathrm{~A}$ & $\mathrm{~A}^{*}$ \\
\hline Colour & Off-white & Off-white & Off-white & Off-white & Off-white & Off-white & Off-white & Off-white \\
\hline Surface & Rough & Smooth & Rough & Smooth & Rough & Smooth & Rough & Smooth \\
\hline Drug content & 98.45 & 99.70 & 98.40 & 99.67 & 98.38 & 99.64 & 98.35 & 99.60 \\
\hline
\end{tabular}


Table 8: In vitro study of A \& $A^{*}$ batches after accelerated stability study

\begin{tabular}{|c|c|c|c|c|c|}
\hline \multirow[t]{4}{*}{ F. code } & \multicolumn{5}{|c|}{ Amount of drug released in different dissolution media } \\
\hline & \multicolumn{3}{|c|}{ pH 1.2} & \multicolumn{2}{|c|}{ pH 6.8} \\
\hline & \multicolumn{3}{|c|}{ Time in Min } & \multicolumn{2}{|c|}{ Time in Min } \\
\hline & 30 & 60 & 120 & 150 & 180 \\
\hline $\mathrm{A}$ & $9.25 \pm 0.04 \%$ & $30.17 \pm 0.01 \%$ & $60.25 \pm 0.05 \%$ & $74.00 \pm 1.18 \%$ & $90.25 \pm 1.21 \%$ \\
\hline $\mathrm{A}^{*}$ & $0 \%$ & $0 \%$ & $4.43 \pm 0.10 \%$ & $47.14 \pm 0.18 \%$ & $98.00 \pm 0.12 \%$ \\
\hline
\end{tabular}

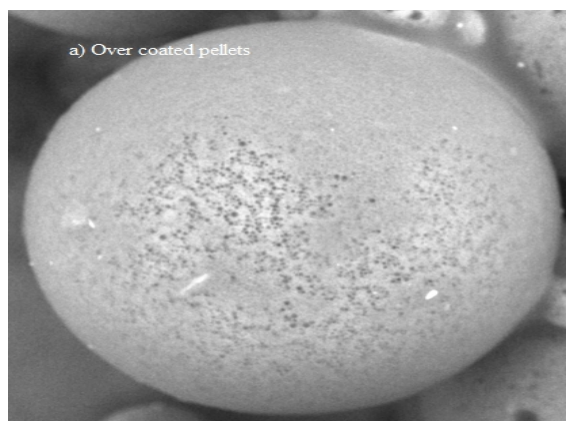

Figure 1: SEM image of over coated pellet

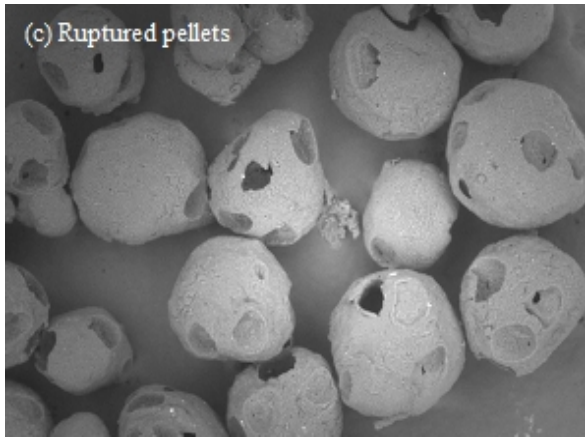

Figure 3: SEM image of enteric coated pellet after stability

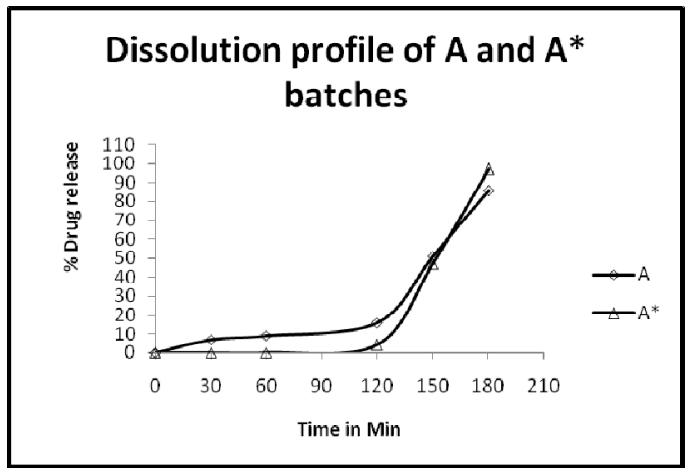

Figure 5: In-vitro dissolution Profile of $A$ and $A^{*}$

This might be owing to an over coat application of HPMC around enteric coated pellets. The friability loss of the all batches was in the range of $0.792-0.751 \%$. The percentage of drug present in the formulations was found to be in the range of $98.45-99.70 \%$ and the loss on drying of pellets was in the range of $1.93-1.94 \%$ respectively. All the parameters evaluated for A and $\mathrm{A}^{*}$ formulations of pellets were given in Table 5.

\section{Gastric resistance and in-vitro dissolution}

The effort of this work was to resist the enteric coated pellets in an acidic environment. The drug release of the pellets coated

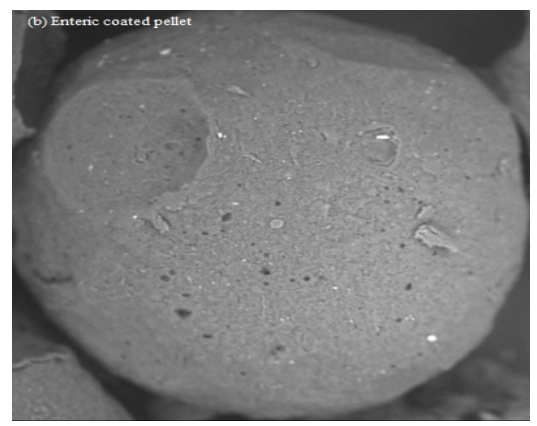

Figure 2: SEM image of enteric coated pellet

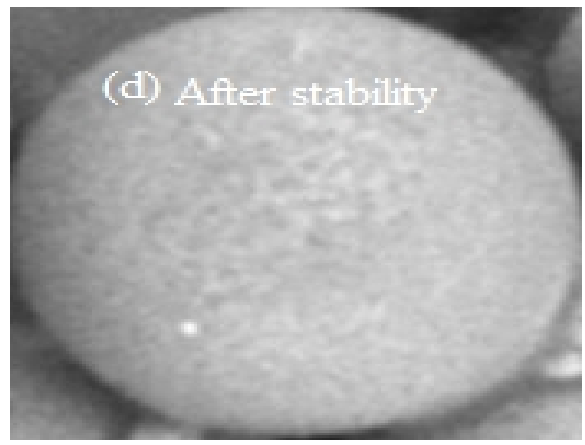

Figure 4: SEM image of over coated pellet after stability

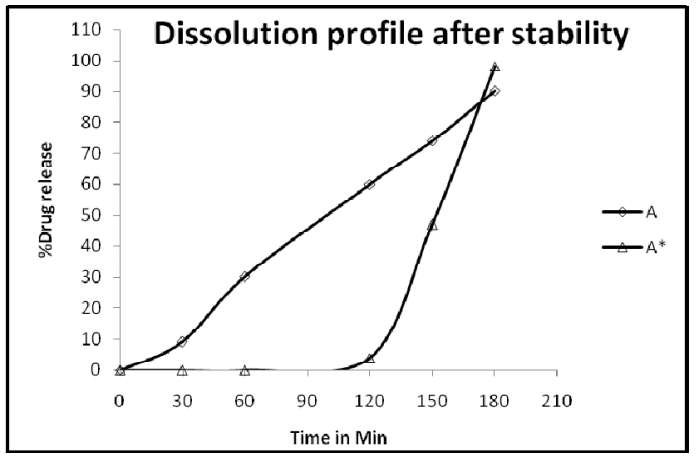

Figure 6: In-vitro dissolution Profile of $A$ and $A^{*}$ at stability period

with HPMC and Eudragit L100 (A) and coated with drug and HPMC layer coat Eudragit L100 and HPMC over coat (A*) was performed for $2 \mathrm{~h}$ in acid media and later in PBS. At the end of $2 \mathrm{~h}$ it was found that only $4 \%$ drug release occurred in group $\mathrm{A}^{*}$ pellets whereas $16 \%$ of drug release was occurred in group $\mathrm{A}$ pellets. The most important properties of the extended release dosage form is its resistance against gastric conditions. It requires that no more than $10 \%$ drug release would occur after 2 $\mathrm{h}$ in $0.1 \mathrm{~N} \mathrm{HCl}$ solution ${ }^{10}$. The results confirmed that over coat application protect the drug in acdic conditions, moreover the over coat application provides uniform shapes Figure 1 and 4. 


\section{Stability studies}

The results for 3 month stability testing revealed no significant change in color, drug content $(98.4-99.7 \%)$. Pellets with only enteric coated alone (A) ruptured surface was observed Figure 3 moreover; more than $50 \%$ of drug were release at the end of $2 \mathrm{~h}$ Figure 5, Table (8). Whereas Pellets with over coated $\left(\mathrm{A}^{*}\right)$ was showed smooth surface Figure 4 and no significant change in drug release pattern Figure 5, Table 8.

\section{CONCLUSION}

Over coating application (HPMC) system on to the enteric coated pellets provided good acid resistance in $0.1 \mathrm{~N} \mathrm{HCl}$. Those pellets exhibited spherical shape with uniform and smooth coating as evidenced by SEM photomicrographs. Based on the result, $0.96 \%$ weight gained over coated pellets provided excellent acid resistance than enteric coated pellets. From the present investigation, it can be concluded that the over coating application system can be used for many acid sensitive drugs to protect them from stomach environment.

\section{ACKNOWLEDGEMENTS}

The authors are grateful to Mr. Nageshwara Rao, Chairman, (Yeluri formulations Hyderabad) for supplying omeprazole, microcrystalline cellulose and disodium hydrogen phosphate as a gift samples of this work. All the authors gratefully acknowledge Mrs. Y. Sujani, Director (Bioleo analytical laboratory Hyderabad) for providing the facility to carry out the evaluation tests of capsules.

\section{REFERENCES}

1. Abdul S, Chandewar A and Sunil B. A flexible technology for modified-release drugs: Multiple-unit pellet system (MUPS), Journal of Control Release, 2010; 147, 2-16.

2. Damanjeet G. Pelletization: An Alternate to Granulation, Pharma Times, 2011; 43: 13-15.
3. Kammili, Varun R. Pelletization technology: A quick review, Journal of Pharmacy \& Pharmaceutical sciences 2011;2:1337-1355

4. Tang E, Chan L and Heng P. Coating of Multiparticulates for Sustained Release: Drug Delivery, 2005; 3: 17-28.

5. Stenhoff H, Blomqvist A, Lagerstrom PO. Determination of the Enantiomers of Omeprazole in Blood Plasma by Normal-Phase Liquid Chromatography and Detection by Atmospheric Pressure Ionization Tandem Mass Spectrometry: Journal of Chromatography B, 1999; 734: 191-201.

6. Singh DH, Roy CS, Verma P, Bhandari V. A review on recent advances of enteric coating, International Organization of Scientific Research Journal of Pharmacy, 2012; 05-115.

7. Patri'cia Severino et al.. Preparation of gastro-resistant pellets containing chitosan microspheres for improvement of oral didanosine bioavailability, Journal of Pharmaceutical Analysis, 2012;2(3):188-192.

8. Noelia L. Gonzalez Vidal, Marta I. V. Brevedan, Maria A. Varillas, Laura D. Simionato, and Maria T. Pizzorno. Effect of accelerated aging conditions on the dissolution stability of ciprofloxacin tablets, Dissolution technologies, 2010; 2: 2329.

9. Wu XY, Eshun G, Zhou Y. Effect of interparticulate interaction on release kinetics of microspheres ensembles, Journal of Pharmaceutical Sciences., 1998; 87: 586-593.

10. Murat T, Hakan V, Mine C. Tableting and Stability Evaluation of Enteric-Coated Omeprazole Pellets. European Journal of Pharmaceutics and Biopharmaceutics, 2004; 57 (2): 279-86.

\section{Cite this article as:}

Swamykannu Dinesh Mohan, Vangadari Rama Mohan Gupta, Yalamanchili Manaswini. Impact of over coat application on enteric coated drug pellets: Designed to protect from stomach environment. Int. Res. J. Pharm. 2016;7(10):14-18 http://dx.doi.org/10.7897/2230-8407.0710115 